\title{
LA ELIPSE: SUBJETIVIDAD NEOBARROCA Y LA ESTÉTICA DEL EXILIO EN LA NOVELÍSTICA DE SEVERO SARDUY
}

\author{
Javiera Anabalón Galiano \\ CECLA-Universidad de Chile \\ javieraanabalon@gmail.com
}

\section{RESUMEN/ABSTRACT}

La obra narrativa del escritor cubano Severo Sarduy, siete novelas producidas en el exilio entre 1963 y 1993, año de su muerte en París, corresponde a un proceso de construcción subjetivo, en el cual identidad individual y nacional coinciden en torno a una interrogante transversal a toda su obra -no solo a la narrativa- que es la pregunta por la cubanidad. Al mismo tiempo, la noción de exilio dentro de su poética neobarroca se dispone como una categoría de orden estético desde donde se estructura su propio relato identitario, el cual se reformula desde la alteridad y subversión que impulsa tal experiencia de la expulsión.

Palabras clave: Sarduy, neobarroco, exilio, cubanidad, identidad, elipse.

The narrative work of the Cuban writer Severo Sarduy, seven novels produced in exile between 1963 and 1993, year of his death in Paris, is a subjective building process, where individual and national identity coincide around one question that is transversal to his whole work -not only to the narrative one-, the inquiry about Cuban identity or "Cuban-ness". At the same time, the notion of exile, inside his neobaroque poetic, results as an aesthetic category type, from where its own identity narration is structured and reformulated from the otherness and subversion that expulsion experience boosted.

KEYWords: Sarduy, Neobaroque, exile, Cuban-ness, identity, ellipsis. 


\section{PALABRAS PRELIMINARES}

El siguiente artículo se basa en un trabajo realizado entre los años 2010 y 2012 sobre la obra narrativa del cubano Severo Sarduy correspondiente a siete novelas producidas en el exilio: Gestos (1963), De donde son los cantantes (1967), Cobra (1972), Maitreya (1978), Colibrí (1984), Cocuyo (1990) y Pájaros de la playa (1993), publicada póstumamente. La transversalidad de tal estudio tenía como objeto reconocer estructuras generales y recursos persistentes que permitieran proporcionar claves de lectura y herramientas interpretativas para su poética y para la escritura neobarroca latinoamericana en general. Dentro de la multiplicidad de géneros en los cuales ha indagado Sarduy, su novelística presenta dos elementos particularmente unificadores, que privilegian de manera considerable dicha revisión paradigmática: el hecho de que todas las novelas fueron producidas en el exilio y que todas se centran en torno a la pregunta por la cubanidad.

El relato sarduyano opera desde el plano material del lenguaje, es decir, primordialmente, desde su dimensión visual, gestual y auditiva y no lógicaracional. El ejercicio de escritura, como el mismo autor ha señalado, se asocia, más que a un ejercicio intelectual, a una actividad de tipo pictórico/ gestual análoga a la práctica del tatuaje, en tanto ésta corresponde a un acto de ciframiento identitario de orden estético-discursivo. Ante esta primordialidad material en la escritura de Sarduy, una aproximación de tipo logocéntrica hacia su obra resulta siempre insuficiente, puesto que ésta opera en la alternancia de géneros y soportes. En sus ensayos sobre el barroco, constantemente su argumentación textual se ve reafirmada con imágenes y gráficos que permiten acceder a su relato desde otros lugares y métodos de comprensión. Frente al objetivo principal de abrir puertas hacia las particularidades de la poética neobarroca sarduyana, las matrices ya mencionadas correspondientes al exilio y a la cubanidad debían encontrar también una transcripción en el plano estético, al igual que aquellas claves de lectura y estructuras subyascentes que se pretendían proporcionar. El artículo, a continuación, resume de cierta manera aquel trabajo anterior de transcripción hacia el plano visual y, específicamente, de aquellos rasgos en la novelística de Sarduy que permiten reconocerla como un gran relato identitario. Si bien no se han incluido en esta ocasión los gráficos e imágenes propuestos en el pasado análisis, se pretende dar cuenta de la plausibilidad de las bases figurativas, no sólo para el análisis de cualquier obra neobarroca, sino que también para el texto académico. 
Por último, es necesario señalar que el exilio, como fenómeno latinoamericano, alberga una cantidad inagotable de claves de comprensión ante los procesos de construcción identitarios que han tomado lugar y de los cuales el arte se ha hecho cargo. La novelística de Sarduy es un ejemplo de cómo el exilio puede pensarse desde la estética y, desde ahí, prestarse como pauta de análisis, no solo de las narrativas latinoamericanas sobre el exilio, sino para cualquier soporte de manifestación cultural.

\section{EXILIO, ESCRITURA Y NACIÓN}

En Reflexiones sobre el exilio (2001), el ensayista y activista palestino Edward Said ha definido la época contemporánea, de guerras, imperialismos y sistemas totalitarios, como "la era del refugiado, de la persona desplazada, de la inmigración masiva" (180), y ha señalado que el exilio se habría convertido en un motivo determinante, e incluso enriquecedor, de la cultura occidental moderna, ya que su desarrollo se debería en gran medida a la obra de exiliados, emigrados y refugiados (179). Durante los últimos siglos, Latinoamérica ha sido un territorio marcado por diversas formas de totalitarismos, los cuales han utilizado sin excepción el exilio como uno de sus principales métodos de represión. Tal ha sido la magnitud de la población latinoamericana afectada, de manera directa o indirecta, por la experiencia del exilio, que éste trasciende el campo semántico geopolítico, para instalarse como matriz de comprensión en otras áreas involucradas en el proceso de construcción -de delimitación- de un sujeto y una identidad latinoamericanos, como es el arte y la literatura en particular.

Said ha abordado los conceptos de exilio, escritura y nación en relación con la interdependencia existente entre los mecanismos de construcción nacional y los discursos de tipo estético que ofrecen un soporte lingüístico y simbólico fundamental para la consumación de aquella idea de nación. El proceso de construcción nacional latinoamericano, cuyo despliegue exigió la colonización, implicó el desarrollo de múltiples formas de nacionalismo, que operaron a partir de una lógica excluyente para definir aquello que "pertenece" o "está dentro" de la nación y lo que no está. Para hacer efectiva esta delimitación y crear los bordes que permiten su existencia, las naciones en construcción buscan una narrativa que plasme aquel ethos selectivo, donde se incluyan elementos retrospectivos y prospectivos, como la historia de padres fundadores, textos básicos cuasirreligiosos, una retórica de pertenencia, sus 
fronteras históricas y geográficas y sus enemigos y héroes oficiales (183). Por otro lado, el historiador y filósofo polaco Leszek Kolakowski señala que el vínculo primordial entre los binomios lengua/idioma y patria/hogar, ha llevado a una identificación metafórica entre el exilio y la práctica escritural, en tanto esta última ha sido interpretada como una experiencia subjetiva de destierro, además de sus implicancias en los proceso de construcción identitaria tanto a nivel individual como colectivo. A partir de tal asociación, se les ha atribuido a los escritores exiliados una condición de "doble exilio" por el hecho de encontrar en la escritura un sustituto lingüístico efectivo del hogar perdido (50-52).

A causa de la expulsión de una gran masa de escritores latinoamericanos, surge en el exilio un extenso conjunto de obras literarias, cuya magnitud y rasgos particulares permiten el surgimiento de una nueva categoría en la literatura Latinoamericana, la "literatura de exilio", y, en lo que respecta a la labor de la literatura en el proceso de construcción identitaria, aparecen en un lugar contrapuesto a las obras reconocidas dentro de la categoría de "literatura nacional". Ante la lógica fronteriza de "nosotros los de dentro" y "ellos los de afuera", el exilio, en oposición a la idea de "integración", a la cual recurren los nacionalismos, también cumple un rol fundamental en cuanto a la construcción de la idea de nación, pero como un relato "Otro" configurado en la experiencia de la expulsión, de la lejanía, de la marginación y desde una fragmentación identitaria individual, que exige una reformulación subjetiva desde la disidencia (Said 184).

\section{EL EXILIO DE SEVERO SARDUY}

El exilio de Sarduy se desarrolla bajo circunstancias particulares, puesto que en primera instancia él deja Cuba por una beca que el Gobierno de la Revolución le proporciona en 1959 para estudiar crítica de arte en Europa, pero luego de cumplirse el tiempo de su beca, Sarduy permanece en Europa, realiza también numerosos viajes por tierras orientales y nunca más vuelve a pisar la Isla. Si bien Sarduy no es expulsado del país, recibe por parte del Gobierno de la Revolución un incentivo para una salida cuyo regreso resultaba complejo: "yo no elegí verdaderamente venir a Europa, como creo que uno elige las cosas" (1795), dice el autor a Emir Rodríguez Monegal en una entrevista realizada en 1977, reconociendo que en su decisión de quedarse reside su mayor posicionamiento político, a partir de lo cual concretiza su 
condición de exiliado. Además, la descarnada persecución que el Gobierno de la Revolución estaba llevando a cabo contra los homosexuales, configuraba un regreso aún más adverso para Sarduy, quien nunca negó su homosexualidad sino todo lo contrario, la reconoció siempre como un aspecto constitutivo de su identidad, tan significativo como su misma cubanidad, la cual resumía como la mixtura de las razas negra, blanca y asiática, específicamente la china. Por tanto, el miedo del escritor no solo residía en su entrada a la Isla, sino sobre todo en la imposibilidad de volver a salir de ella, como quedó registrado también en la entrevista de Joaquín Soler Serrano de 1976. Independiente del pesar que puede haber significado para Sarduy el alejamiento de su tierra natal, resulta indiscutible el hecho de que en su obra el exilio opera como una experiencia que tiene como consecuencia un reforzamiento identitario, puesto que su distanciamiento de Cuba propulsa un proceso consciente de construcción subjetiva, el cual Sarduy cifra y lleva a cabo en su narrativa neobarroca. En este sentido, la experiencia del desarraigo en Sarduy tiene un efecto paradójicamente aproximativo, ya que el proceso de reconocimiento de su centro originario, implica un contradictorio traslado hacia la periferia. El mismo autor ha señalado que el acto de distanciamiento le brinda una nueva ruta de acceso a la cubanidad:

Al distanciarme de Cuba comprendí qué era Cuba, o al menos me plantee con toda claridad la pregunta: ¿Qué es Cuba? (...) creo que nadie, en el interior de Cuba, podría resolver esa cuestión con total pertinencia puesto que estando dentro de su contexto, el contexto en sí es indefinible. (...) Cuba era algo que estaba demasiado presente; no podía saber qué era. Cuando quedó lejos, pude empezar a plantearme esa pregunta, que es la que poco a poco ha centrado mi trabajo. A saber: cuáles son las posibilidades, diría de un modo un poco presuntuoso, las posibilidades ontológicas, las posibilidades de ser de mi país ("Severo Sarduy" 1797).

Uno de los aportes más significativos que Said identifica en la experiencia del exilio tiene relación con la nueva perspectiva de la propia cultura que la lejanía otorga al sujeto, al mismo tiempo que la aparición del "Otro" la pone en crisis y delimita sus contornos. Pero desde la condición de exilio, en tanto experiencia de expulsión, de rechazo, aquella nueva perspectiva exige la configuración de un nuevo discurso, de una nuevo constructo subjetivo acuñado ahora en la marginalidad. Es necesario señalar que no obstante los beneficios que la experiencia del exilio pudiera presentar, Said deja en claro, 
conforme a su propia experiencia como exiliado, que, a la escala como se ha dado este suceso durante el siglo XX y siendo un método de represión que atenta indiscutiblemente contra los derechos humanos, la experiencia del exilio no es ni estética ni humanísticamente comprensible, por lo cual pensar el exilio como algo beneficioso para las humanidades, a partir del enriquecimiento que pudo significar para cierta literatura por ejemplo, sería trivializar en muchos aspectos sus mutilaciones (Reflexiones 180). Frente a esto, Said subraya que aquello que puede haber resultado enriquecedor de tal contexto de desarraigo es producto únicamente de una fortaleza, creatividad y resiliencia, surgidas siempre desde una consternación, cuya profundad lo hace inefable en gran medida. Son los procesos subjetivos de reformulación que la experiencia del exilio trae consigo y el registro histórico y estético sistemático llevado a cabo por parte de los pueblos e individuos afectados, lo que hace posible que el exilio pueda operar luego como una matriz de comprensión para la situación latinoamericana o como una categoría estética. El exilio es un método de represión que en cierta medida demuestra un efecto contraproducente, dado que gesta necesariamente un nuevo relato revolucionario o alternativo de identidad, tanto en un ámbito individual como colectivo o nacional.

\section{IDENTIDAD LATINOAMERICANA, CUBANIDAD Y NEOBARROCO}

El término "neobarroco", si bien ha sido definido muchas veces como una reedición latinoamericana de una estética europea del siglo XVII, ha encontrado siempre un terreno dificultoso y complejo a la hora de definirse, principalmente por las discusiones surgidas en torno a la validez del vínculo que establecería con el barroco europeo y la dificultad que presenta dicha estética a la hora de tratar de comprenderla como propiamente latinoamericana. En términos muy generales diremos, en esta ocasión, que el neobarroco corresponde a una perspectiva, a una forma de comprensión y de percepción del arte y la vida, instalada y desarrollada en Latinoamérica a partir de la colonización, cuya base se articula sobre la conciencia de la representación como acto de significación. Aquellas obras que se inscriben dentro de la línea del neobarroco demuestran un enfoque autorreflexivo o autocontemplativo sobre los propios procesos de construcción de sentido y sobre las dinámicas y recursos materiales que las constituyen, tanto en la forma (plano significante), como en el fondo (plano del significado). 
La estética neobarroca aparece como una perspectiva privilegiada desde donde representar la experiencia latinoamericana y la problemática en torno a la identidad, que surge a partir de la colonización y así, también en referencia al caso específico de Sarduy, para la pregunta por la cubanidad. Afirma Gerardo Mosquera: "El latinoamericano ha tenido siempre que preguntarse quién es, simplemente porque resulta difícil saberlo. Se confunde entre Occidente y No Occidente al participar de ambos en sus comienzos históricos. No ha conseguido asumir su 'inautenticidad', por lo que necesita afirmarse mediante relatos que lo ontologicen" (270). La herencia europea en Latinoamérica corresponde no tanto a la "revelación" de una identidad latinoamericana ante la aparición contrastante de un Otro, como a la instalación de la necesidad de ontologización misma. El problema de la inefabilidad latinoamericana surge de una necesidad logocéntrica importada desde Europa e implantada a través del lenguaje castellano fundamentalmente que, además, trae consigo un concepto de identidad asociado a la permanencia, a la conservación, de ciertos rasgos genéticos a lo largo del tiempo, a partir de lo cual resulta imposible pensar una identidad latinoamericana concebida en lo mestizo y, como señala el etnólogo Fernando Ortiz, "inherentemente variable" (El engaño 130).

Antes de continuar, sería pertinente precisar algunos aspectos en torno al concepto de identidad y bajo qué nociones éste opera al interior de la obra sarduyana. Puesto que el sentido de identidad tanto individual como cultural, en tanto experiencia compartida, se manifiesta principalmente en el lenguaje, existe una relación directa entre el concepto de representación, y por lo tanto de construcción, y el de identidad. La pregunta de Sarduy por Cuba se formula, desde un inicio, no en función del reconocimiento de un objeto real, el cual hay que descubrir y describir por medio del lenguaje, sino desde las maneras y recursos a partir de los cuales Cuba puede ser narrada o representada, en otras palabras, cómo hacer emerger a Cuba en el texto. Dicho lo anterior, una de las definiciones del concepto de identidad que resulta útil para el presente análisis corresponde a la propuesta por el sociólogo Jorge Larraín:

[P]roceso de construcción en la que los individuos se van definiendo a sí mismos en estrecha interacción simbólica con otras personas (...) la capacidad de considerarse a uno mismo como objeto y en ese proceso ir construyendo una narrativa sobre sí mismo (...) un proyecto simbólico que el individuo va construyendo en íntima relación con los grupos sociales dentro de los cuales se desenvuelve (72-73). 
También Fernando Ortiz en su obra El engaño de las razas (1946) expone la inviabilidad de la existencia de las llamadas "razas puras", entendidas bajo el criterio de la permanencia de los elementos genéticos traspasados de generación en generación. Ortiz afirma que los caracteres comunes en un grupo humano no son permanentes si no variables: "permanencia y mudanza, continuidad e interrupción, actividad y descanso, ser lo uno pasa a ser lo otro. Pausas, movimientos; es el ritmo de la vida universal. Estabilidad y variabilidad. Todo dura y todo muda" (130). La inestabilidad, que se identifica con el exilio, el barroco y la obra de Sarduy, se relaciona de manera estrecha con lo expuesto por Ortiz y, del mismo modo, confirma su distancia con cualquier noción esencialista de identidad. En consonancia con las proposiciones de Larraín y Ortiz, el concepto de Sarduy sobre la identidad presenta entonces dos aspectos fundamentales que resultan imprescindibles a la hora de abordar su obra: la identidad es algo que se encuentra en permanente cambio y que nunca deja de construirse. Mientras sea un asunto desplegado en el plano estético, dicha noción se vincula directamente con las ideas de "proceso", "inestabilidad" e "incompletitud", las cuales también atañen tanto al concepto de exilio como al de neobarroco.

El neobarroco se desarrolla en el escenario latinoamericano como la estética de "lo que está en camino a", lo que permanece en la espera -y por lo tanto en el deseo- de un nombre esquivo, que nunca se manifiesta del todo y que por tanto termina olvidándose. La operación neobarroca corresponde al desplazamiento del sentido y su operatividad desde el objeto hacia su instancia de manufactura, de configuración, permitiendo con ello el despliegue de un arte que comprende y representa la identidad latinoamericana como un conjunto de procesos, en cuyo lecho dinámico y cambiante Latinoamérica se ve a sí misma, en un vaivén perpetuo de definición entre culturas, como señala Mosquera. Volviendo a lo referido respecto del rol que imparte la literatura en la construcción de relatos identitarios, no resulta curioso el hecho de que el neobarroco latinoamericano haya encontrado en la escritura uno de sus nichos más prolíficos, sin embargo, aun cuando ha sido la literatura su soporte más frecuente, sigue siendo una estética abocada a las dimensiones materiales -sonoras y visuales- del lenguaje.

Así como el neobarroco ofrece posibilidades estéticas ante la problemática identitaria latinoamericana, aún más pertinente resulta para abordar el caso de Cuba, donde la pregunta por la identidad surge de una borradura radical, de un vacío original como resultado del genocidio de la totalidad de la población nativa llevado a cabo durante la colonización. La gran masacre 
despliega procedimientos de repoblamiento -tanto de "dominadores" como de "dominados"- y de reconstrucción nacional a partir de la inmigración y del fenómeno de transculturación, el cual, señala Ortiz, resulta fundamental para comprender y analizar la cubanidad (Contrapunteo 96). El exilio, la diversidad cultural y el mestizaje son los elementos que han determinado la totalidad de los procesos culturales, políticos y sociales en la historia de Cuba; la cubanidad es una identidad que, de manera paradójica, se constituye en la experiencia misma del desarraigo, de lo foráneo, al igual que en continuos procesos de integración. El etnólogo cubano Rodríguez Rivera, en su libro Por el camino del mar. Los cubanos (2005) se refiere a un pueblo cubano moldeado en la experiencia del encuentro con lo extranjero:

Cuba es un tipo de sociedad abierta que en menos de una generación convierte en cubano (lo "aplatana", se dice en el país) al extranjero que se integra a ella (...) Acaso por ello, y por ser la Isla un natural cruce de caminos, el cubano ha sido un pueblo para el cual resulta familiar lo internacional y que ha tenido, por ejemplo, líderes extranjeros con quienes fue capaz de arriesgarse en duras batallas y también respetó y admiró más que a muchos cubanos de nacimiento (20).

En De donde son los cantantes (1967), la segunda novela de Sarduy, Flor de Loto, Dolores Rondón y El General, corresponden a tres alegorías de los constituyentes etno-culturales de la cubanidad y con los cuales Sarduy se identifica plenamente: lo chino, lo africano y lo español, respectivamente, cuya interacción implica el diálogo entre tres unidades textuales, tres discursos culturales y tres cuerpos, que se desean y buscan entre sí. El carácter erótico, a partir del cual se recrea el proceso de mestizaje en De donde son los cantantes, instala además la problemática identitaria en un terreno de juego/lucha de poderes, de territorialidades, de estrategias de conquista y de diálogo. En este relato, Sarduy expone, de manera particular, un concepto de identidad, una cubanidad, como un fenómeno fundamentalmente múltiple, cambiante y móvil, asociado siempre a lo intermedio, a los trayectos, al igual que la misma latinoamericanidad. En este sentido, Cuba deviene una metonimia de la condición fundamentalmente intermedia y móvil de la identidad latinoamericana, al mismo tiempo que Sarduy deviene metonimia de Cuba y su obra, otra de sí mismo. Latinoamérica, Cuba, Sarduy y su novelística conforman una figura de círculos concéntricos atravesados por la matriz del exilio, que establece una multiplicidad primordial en el centro de toda posibilidad de ser en el cosmos neobarroco sarduyano. 
Said remarca el error en la idea de que exilio signifique un desligamiento total del país de origen, incluso manifiesta su deseo porque fuera efectiva aquella separación quirúrgicamente limpia con la patria. Pero lo que ocurre es que el exiliado mantiene un inquebrantable vínculo con su origen, el cual se manifiesta constantemente en tensión con el nuevo territorio de residencia. Afirma Said: "El exiliado existe, pues, en un estado intermedio, ni completamente integrado en el nuevo ambiente, ni plenamente desembarazado del antiguo" (Representaciones 68). La coexistencia de contextos instala al exiliado en un estado de fluctuación que determina para siempre sus procesos de construcción subjetivos, los que comienzan a concebirse sobre una base dialógica que permite desarrollar una cierta consciencia de lo propio a partir del contraste con lo Otro: "Ver el mundo entero como una 'tierra extraña' permite adoptar una mirada original. La mayoría de la gente tiene conciencia principalmente de una cultura, un escenario, un hogar; los exiliados son conscientes de al menos dos, y esa pluralidad de miradas da pie a cierta conciencia de que hay dimensiones simultáneas, una conciencia que es (...) contrapuntística" (Said, Reflexiones 194). Pero esta duplicación de perspectivas que experimenta el exiliado no solo establece una nueva dualidad en las bases de su construcción subjetiva, sino que lo somete también a un estado de diálogo, de resolución discursiva sobre el conflicto que se establece en dicha base dual.

En el plano literario, la dinámica dialógica, cuyo origen Mijail Bajtín reconoce en la sátira menipea y en el diálogo socrático, corresponde al principio fundamental de la obra de Sarduy, y puede observarse en todo nivel de significación. Todo en Sarduy es de carácter doble, desde los personajes hasta las bases compositivas en su narrativa, como es el caso de las novelas Cobra (1972) y Maitreya (1978), las cuales, curiosamente, corresponden también a la bisagra de la narrativa del cubano y juntas describen una estructura de tipo especular. También la figura del travesti corresponde a una de las unidades simbólicas primordiales en su obra completa, puesto que consagra y exhibe de manera espectacular la multiplicidad y el proceso como posibilidades subjetivas, al igual que dicha dinámica dialógica, estado de tránsito perpetuo, producto de la coexistencia de elementos diversos en un mismo cuerpo de significación. Podría decirse que la escritura sarduyana deviene travesti en sí misma, puesto que para Sarduy ésta corresponde a una actividad erótica, un arrebato de orden sexual, cuya huella es el testimonio de un merodeo eterno entre un género y el otro, un sexo y el otro, un Yo y el Otro, una patria y la otra. El exilio hace patente de manera trágica en el individuo su estado de discontinuidad (tomando el término de George Bataille), por lo cual inserta 
en él la necesidad del ejercicio de re-unión, de unificación, de búsqueda de continuidad $^{1}$. Y el acto de enlace, el encuentro, la efectividad del traspaso, sucede siempre en la grieta, en los espacios intermedios, en el trayecto entre un foco y otro.

\section{PARODIA Y EXILIO: LA ESTRATEGIA SUBVERSIVA Y EL DESDOBLAMIENTO DISCURSIVO}

El desdoblamiento identitario que experimenta Sarduy en el exilio es llevado al plano textual por medio del recurso de la parodia, a través de la cual el autor logra introducirse en el texto como un significante más y llevar a cabo el ejercicio de distanciamiento y reapropiación de sí mismo en ese plano, del mismo modo como sucede con Cuba cuando logra mirarla desde la nueva perspectiva que ofrece el exilio y plasmarla en su narrativa. Por medio de la parodia, Sarduy puede cifrarse a sí mismo en su proceso de construcción como escritor y como cubano y observarse deambulando entre sus relatos:

Cuando yo digo en mi novela: yo, ese yo es un él. Es decir: toda primera persona singular en una novela es un él (...) yo he querido jugar en mi novela con esa ambigüedad, y diría que en ella intervienen dos yo: uno al nivel de ese personaje escritor y otro al nivel de yo mismo, que también juzgo a ese yo autor. Así mismo, interviene en la novela un lector que es una especie de caricatura de lector" ("Severo Sarduy" 1805) $)^{2}$.

La parodia lleva a cabo una reexhibición burlesca de las características propias de un elemento o entidad, pero exige un ejercicio previo de reconocimiento para que sea posible aquella puesta en crisis y deformación. Este reconocimiento puede llevarse a cabo en la medida en que exista un ejercicio de distanciamiento

\footnotetext{
A propósito del universo carnavalesco, Bajtín afirma que el sistema de oposiciones binarias supone una relación interna previa u "original" entre los polos de la oposición, la cual resulta irrepresentable por su propia imposibilidad de restitución, y sin la cual, como, dicha oposición carecería de todo sentido y sería incluso irreconocible.

2 En entrevista de Emir Rodríguez Monegal publicada en 1977 en El arte de narrar, recogida en la obra completa de Sarduy.
} 
que permita reconocer los constituyentes y contornos que circunscriben a tal elemento o entidad como particularidad.

En tanto la narrativa de Sarduy tiene como característica principal el hecho de ser un proceso continuo que va y viene sobre sí mismo, la parodia permite al autor rearmar una y otra vez la imagen construida en cada novela, con respecto a lo cubano y a sí mismo, al mismo tiempo que los límites de las obras se ven franqueados por los personajes, quienes deambulan y reaparecen metamorfoseados a lo largo de toda la novelística como auténticos dueños del relato. Como dice Bajtín, muy en sintonía con lo que menciona Ortiz con respecto a la identidad, el propio discurso es siempre en alguna medida parodia de otro discurso/identidad precedente, como cada nueva novela en Sarduy deviene una parodia de un relato suyo anterior: "El yo es desde sus orígenes algo híbrido, un cruce, un bastardo. La identidad es un injerto (...) Llegamos a nuestro 'propio' discurso a través de un itinerario que desde la repetición, imitación, estilización del discurso ajeno, lleva a ironizarlo, parodiarlo y criticarlo" (Cit. en Rojas 77). Podría pensarse que el recurso de la parodia, como estrategia de apropiación, es al texto, como el exilio a la patria. Tanto el exilio, en el plano experiencial, como la parodia en el plano textual, conllevan un periodo inicial de pérdida y despojo que luego es remplazado por otra fase de reapropiación. La parodia, entonces, se convierte en una táctica de recuperación factible en el plano lingüístico, como una suerte de sanación que permite regresar desde otro lugar al origen; como una segunda oportunidad donde todo puede volver a ser nombrado por primera vez.

La parodia, como manifestación discursiva del exilio y del desdoblamiento subjetivo, dota al relato sarduyano de una alta densidad política. González Echeverría se refiere a la facultad crítica y política de la parodia, en tanto opera siempre en un terreno de lucha con el poder, problematizando la validez de los discursos hegemónicos: "La parodia es agresión contra el modelo, contra la tradición, contra la memoria sobre la cual se inscribe el texto. Al tachar el modelo, el origen, el padre, la constitución de la novela se ofrece como si fuera autónoma, como si no estuviera centrada por los límites de esa tachadura" (Memoria 1755). Sergio Rojas, a propósito del carnaval, se refiere a la incidencia de la parodia en el proceso de construcción identitaria de un pueblo, pero vinculado, además, al acto de resistencia que permite un aparecer de la identidad en la contraposición del pueblo con la autoridad como un "otro": "Se trata pues, de la producción de 'identidad' de aquél que sólo puede objetivarse a sí mismo (...) alterando las formas sancionadas por la autoridad o por los patrones culturales dominantes" (76-77). Lo señalado por 
Rojas puede visualizarse en el ejercicio intelectual del exiliado, del modo como lo propone Said, en tanto éste ofrece una "poética de la alteridad" que surge desde un espacio opuesto y a la vez crítico del centro hegemónico represor.

Así como Sarduy distancia su obra del género autobiográfico por medio de textos que lo parodian, como El Cristo de la Rue de Jacob (1987), entre muchos otros, también se distancia, como afirma Guerrero, "del culto romántico a la figura del escritor y de su mistificación contemporánea a través de las campañas de promoción editorial que han acabado convirtiendo a los autores en atracciones de feria, cuando no en marcas registradas"3. Para Sarduy, las clasificaciones y jerarquizaciones al interior del arte y en el ámbito literario en particular repercuten de mala manera en la creatividad de los autores y en la autonomía de la obra, puesto que dichas categorías y estatutos conducen a los autores muchas veces a caer en formatos y temáticas complacientes y comerciales. Un ejemplo de ello corresponde al radical distanciamiento que ha demostrado el cubano con respecto al conjunto de obras literarias identificadas como el Boom latinoamericano ${ }^{4}$, al igual que sus apreciaciones sobre el Premio Nobel. De esta manera, Sarduy no solo parodia y se distancia de las formas tradicionales de escritura latinoamericanas, sino que también de los protocolos instalados en el ambiente literario latinoamericano ${ }^{5}$, al igual que de las instituciones que los avalan. Será pues en este ejercicio paródico donde se manifestará gran parte del carácter estratégico del exilio en la obra de Sarduy.

3 Guerrero, Gustavo. “Severo Sarduy”. Letras Libres. 01.2004.12.2011 http://www. letraslibres.com/revista/entrevista/severo-sarduy-0. Guerrero cita también a Juan Goytisolo, gran amigo de Sarduy, al igual que Guerrero, quien ha señalado: "Severo Sarduy se tomaba a sí mismo en broma y afrontaba con rigor y escrupulosidad ejemplares su quehacer literario".

Roberto González Echeverría menciona con respecto a este tema: "La a veces tirante situación sin duda contribuyó a exacerbar las diferencias entre Sarduy y los escritores del llamado boom. Éstos se erguían como el final apoteósico de la búsqueda de identidad latinoamericana, ese gran tema de origen romántico que vertebra la literatura hispanoamericana del siglo que ahora termina. Para éstos había una deseada Latinoamérica que alcanzaba su plenitud política en Cuba. Para Sarduy, Cuba, concebida como la trágica encrucijada histórica antes descrita, no podía ser sino un agente disgregador, jamás acogedor" (Plumas 1590).

Algunos ejemplos en que Sarduy ha parodiado todas estas formas de autobiografía, que también parodian de paso la construcción de la imagen idílica del autor son: la entrevista que le concedió a Mihály Dès en 1990, "Para una biografía pulverizada en el número -que espero no póstumo- de Quimera", y, de ese mismo año, "Lady S.S.", su autorretrato en traje de diva o de rumbera; son dos buenos ejemplos de esta postura crítica ante lo testimonial y lo íntimo, además de la ya mencionada para-biografía: La rue de Jacob (1987). 
Por último, es importante señalar que el recurso de la parodia, en su ejercicio de deformación, de volver a nombrar desde otro lugar, trae consigo el rasgo transgresor, subversivo, substancial de la perspectiva barroca vinculada a lo que Bataille llamó en su obra La Parte Maldita (1987) "gasto improductivo". En la entrevista dada a Soler Serrano, Sarduy da una suerte de definición sobre lo barroco asociada a esta potencia desestabilizadora y revolucionaria y a dicha noción de gasto: "Sé lo que no es barroco (...) no se trata de un puro juego verbal, no es un ejercicio frívolo de juegos de palabras, se trata de amenazar el soporte central de la sociedad que es la economía, que ya es mezquindad". El barroco se asocia a la transgresión en tanto despilfarro, extenuación, en su dinámica del gasto, su lógica del proceso amenaza el discurso económico imperante basado en el concepto de productividad. Como señala Sergio Villalobos recordando La modernidad de lo barroco de Bolívar Echeverría, "la semiosis barroca funcionaría como gasto improductivo que altera y confunde la transparencia del ethos racionalista y su antropologos, el homoeconomicus como reducción de lo humano a una función de la producción y el consumo (...) pensar críticamente la homologación de capitalismo y modernidad, es postular una modernidad barroca, no capitalista" (3): una suerte de "altermodernidad". La autorreflexividad neobarroca es lo que inscribe esta estética en el ámbito de lo improductivo, es decir, aquello que es fin en sí mismo y no medio para alcanzar un objeto que le trasciende. El sentido en la escritura neobarroca no es "otro" que el proceso de escritura mismo, el lenguaje mirándose en su acto de ciframiento, desmarcándose una y otra vez de sus referentes comunes al volverse sobre sí mismo. El barroco es revolución pura, el lado B del discurso logocéntrico y capitalista imperante; representa la crisis en la historia del pensamiento occidental, a través de la reivindicación de los sentidos y la percepción como método legítimo de conocimiento.

\section{LA ELIPSE NEOBARROCA}

En el terreno del lenguaje, la dualidad básica se encuentra dada por la oposición entre significado y significante, pero, puesto que en el neobarroco el significado describe una disolución, o más bien, un traspaso hacia el plano significante, el diálogo propio del signo lingüístico sausseriano, en esta estética, encuentra un nuevo campo operativo en la metáfora: figura barroca por excelencia, cuyo método sustitutivo se propone como única posibilidad de referir, colmada 
en el acto de representar mismo, sin pretensiones de dar con el centro (con el nombre absoluto), para, por el contrario, evadirlo. En su ensayo Barroco (1974), Sarduy identifica la metáfora con la figura del círculo, dado que la cadena de significantes, equivalente al perímetro, aparece para la sustitución de un sólo nombre original y estable correspondiente al punto central. Dos metáforas referentes de un mismo objeto describen un vector equidistante de un centro común, por lo tanto, mantienen la estabilidad y uniformidad de la órbita a su alrededor. En Barroco, Sarduy describe la figura de la metáfora:

La metáfora es el traslado, la mudanza retórica por excelencia, el paso de un significante, inalterable, desde su cadena "original" hasta otra, mediata, y de cuya inserción surge el nuevo sentido - Figura logocétrica: supone que hay un sentido y que se desplaza, pero aún en el interior del desplazamiento el logocentrismo se salva en la medida en que hay un sentido propio y un centro: figura de la conservación. Como la metáfora la rotación circular es la única traslación de los cuerpos que garantiza su inalterabilidad, la invariabilidad de la distancia que los separa de un centro que los anima y conforma (1222).

Cuando se produce la escisión de ese centro, unitario y estable, cuando se duplica y desplaza, la esfera sufre una deformación y aparece la imagen de la elipse, cuya proyección en el espacio retórico según Sarduy, recae en la elipsis. Ambas figuras, la geométrica y la retórica, corresponden a una órbita dibujada alrededor de dos centros, uno visible y otro obturado. Sarduy señala que en el código retórico la elipsis corresponde a la supresión de uno de los elementos necesarios para una construcción completa, pero que en un registro más amplio corresponde a la supresión en general, es decir, al ocultamiento teatral de un término en beneficio de otro que recibe luz abruptamente (Barroco $1230)^{6}$. Es importante recalcar el carácter artificioso de la desaparición de

6 Esta noción de la elipse se hace evidente en la técnica barroca del claroscuro a partir de la cual los cuerpos emergen a la superficie -aparecen-gracias a una luz oblicua que no logra iluminar la totalidad de los cuerpos ni de la escena, conforme al concepto de "objeto parcial" que nunca se deja ver completo. Lo que resplandece emerge gracias a la penumbra de lo otro: "Lo que vemos en la representación barroca es lo que se alcanza a ver, vemos lo que sale desde lo oscuro, pero también en cuanto que no termina nunca de salir totalmente (...) oscuridad que recorta el contorno de lo visible, pues lo visible, lo que aparece, no lo hace desde los límites con lo oscuro" (Rojas 199). 
uno de los dos centros, ya que el ocultamiento no significa su desaparición y el rasgo de dualidad permanece.

La principal vinculación entre el concepto de exilio y la imagen de la elipse, que permite, además, comprender la dimensión estética del término, tiene relación precisamente con la aparición de ese nuevo centro: el establecimiento del binomio como centro, que rompe para siempre con las nociones de fijeza, estabilidad y permanencia con las cuales éste y otros conceptos, como "identidad", "realidad" y "sentido", se han identificado. Dice Sarduy, con respecto a su propia experiencia de exilio: "Si el centro es un yo monolítico, central, único, irradiando su discurso hacia espacios siempre a igual distancia, la superficie que estos determinarían sería una esfera perfecta (...). El yo se ha escindido, el haz que lo constituye -así lo percibe el Budismo- se ha esparcido: fractura del monólogo" (La Simulación 1318-1319).

El sentido que brinda la figura de elipse no tiene que ver tanto con la duplicación de su centro, como con la tensión y movimiento que se instala en aquel centro a partir de esa duplicación, y que termina con la posibilidad de la quietud que ofrece lo unitario. Así mismo el exilio no tiene que ver tanto con la coexistencia de las dos patrias, como con las maniobras de integración que el individuo debe llevar a cabo para el resto de su vida. Como menciona Said en Representaciones del intelectual (2007), "El intelectual exílico no responde a la lógica de lo convencional, sino a la audacia asociada al riesgo, a lo que representa cambio, a la invitación a ponerse en movimiento y no a quedarse quieto" (82). El exiliado debe mantenerse en guardia, pues el confort y la seguridad excesivos significan una amenaza. La noción de llegada, de conclusión y de descanso se anulan y la única posibilidad de fijeza corresponde al movimiento eterno, al igual que el móvil que, por su incapacidad de cerrar el círculo, se eyecta eternamente al trayecto de la elipse. El exilio desde la imagen de la elipse se propone como una vida "sacada de su órbita habitual", una experiencia que implica la pérdida, la expulsión, la marginalidad y la "deformación" de la subjetividad, lo cual en el caso de Sarduy queda cifrado en su obra, como un tatuaje impreso en el cuerpo textual. Dice Said:

[Los] exiliados son siempre excéntricos que sienten su diferencia (...) como una especie de orfandad. (...) aferrándose a la diferencia como un arma que hay que emplear con la voluntad endurecida, el exiliado o exiliada insiste celosamente en su derecho a negarse a ser aceptado (...) La compostura y la serenidad son las últimas cosas que se asocian con la obra de los exiliados. Los artistas en el exilio son 
decididamente desagradables y su obstinación se insinúa incluso en sus exaltadas obras (Reflexiones 189).

Sarduy, antes de recibir la beca del gobierno cubano, había estudiado medicina y luego, en Europa, siguió desarrollándose en el ámbito de la ciencia como periodista científico. Tan cerca como estuvo del arte, siempre lo estuvo de la ciencia también. El resultado del trasfondo multidisciplinario de Sarduy deviene una poética que exhibe la relación de interdependencia existente entre las ciencias y el arte; el modo en como la ciencia se sirve de la metáfora y de las alegorías visuales para comunicar al mundo e interpretar lo que la tecnología y el esquema de pensamiento, en tal o cual período de la historia, permiten comprender. La obra de Sarduy siempre ha manifestado el retombé (eco), el diálogo existente entre ambos ámbitos disciplinarios, como dos superficies reflectantes una de la otra, como una puesta en abismo de representación.

En su ensayo de 1987, Nueva Inestabilidad, Sarduy hace una lectura cosmológica del barroco y del neobarroco, a través de una revisión de los diversos esquemas cosmológicos que los científicos han presentado a lo largo de la historia occidental, los cuales Sarduy describe como estructuras especulares y al mismo tiempo determinantes del pensamiento de una época y de todo su sistema simbólico de representación. El requerimiento de la estabilidad que otorga la comprensión de un determinado ordenamiento del universo (cosmos) se habría traducido en la multiplicidad de bosquejos que han presentado los astrónomos sobre el universo, basados en estructuras e imágenes reconocibles, las cuales han permitido explicar aquello que resulta inabarcable para el pensamiento, como es el universo en sus vastas dimensiones. Para tal objeto, la ciencia se ha servido del arte, puesto que los científicos han tenido que recurrir a la poesía y, específicamente, a la figura de la metáfora, para poder darles cabida en el imaginario de la época:

El terreno de metáforas por el que avanza la cosmología para llegar a constituir su inconcebible imagen final está plagado de seres tan vistosos como las enanas blancas, las enanas negras, las gigantes rojas, las viajeras azules y los huecos negros (...) que van de la decena a la centena de megaparsecs, (...): todo llega a constituir una estructura que se define bien "en forma de colmena", o bien como algo "espumoso", "esponjo", o en forma de "queso suizo" (...) La maqueta, como se ve, domestica al universo, lo hace literalmente, manipulable, gracias a un juego de metáforas destinadas a familiarizar lo inconcebible, 
y en las cuales la fértil imaginación de los astrónomos siempre ha sido pródiga (Nueva 1366).

Sarduy entiende el barroco como un sistema de interpretación que condiciona los modos de entender, conocer, ordenar y aprehender el mundo en un tiempo determinado de la historia, lo que Michael Foucault identifica con el término de episteme en Las palabras y las cosas (1966) (7). El dibujo cosmológico corresponde a la representación figurativa de los límites, o bordes, del pensamiento en un momento de la historia determinado, y es la figura de la elipse la que narra la experiencia de la crisis, de la duda de una época en donde toda verdad se vuelve opaca. Señala Sarduy al respecto:

La Maqueta, pues, permite la observación, pero al mismo tiempo la vuelca en el reflejo especular o la anula en una pura tautología: la mirada del observador $y$, por supuesto, a su propia mirada, (...) esto no ocurre más que en un momento preciso, como si la propia maqueta implicara, en el curso de su evolución, la necesidad de contemplarse, de ser observada. O dicho en términos: como si el universo tuviera sentido (Nueva 1368).

Así como la era heliocéntrica encuentra su reflejo geométrico uniforme y estable en la imagen del círculo, la teoría de Johannes Kepler lo hace sobre las elipses (1609-1618) trayendo consigo la alteración, la desmedida y la incompletitud propia del barroco, puesto que la elipse resulta de la deformación del círculo y aparece como una perturbación a su uni-formidad, presentándose como figura de transgresión en el traspaso de un modelo unicéntrico a uno pluricéntrico. La teoría de las elipses de Kepler es uno de los eventos más revolucionarios y detonantes del gran cambio epistemológico del renacimiento hacia el barroco. Junto al descubrimiento de un "Nuevo Mundo", la Reforma Protestante, la teoría cartesiana, entre otros sucesos críticos de la época, la transmutación del esquema cósmico circular hacia uno elíptico aparece en la cultura occidental del siglo XVII como el desmoronamiento de todo lo hasta ese entonces certero sobre la realidad, lo cual por cierto se manifestó como un nuevo paradigma simbólico en el arte de la época. "El cielo organizaba la tierra. Astros y órbitas dibujaban con sus trayectos elípticos, la geometría invisible de los cuadros, la maqueta de las catedrales, la voluptuosa curva que en un poema evita el nombre, la designación explícita y frontal, para demorarse en la alusión cifrada" (Sarduy, Nueva 1347-1348). 
Resulta importante señalar que la ya mencionada identificación que hace Sarduy entre la figura retórica de la metáfora y la figura geométrica del círculo no tiene que ver con que la metáfora sea una figura propia de una perspectiva conservadora, sino que refiere a un estado previo a la elipsis en el plano retórico - $\mathrm{o}$ a la elipse en el plano geométrico/cosmológico- necesario para su establecimiento, al igual que para su carácter revolucionario. La figura de la elipse encarna el triunfo de "lo Otro", de la deformidad, de lo múltiple por sobre lo unitario, de lo móvil por sobre lo estático, es el símbolo de la crisis misma. El neobarroco en Latinoamérica transmuta esa perspectiva crítica del barroco europeo hacia una estrategia de construcción identitaria, en donde la figura de la elipse, desde el contexto en que se instala en Europa del siglo XVI y XVII, se presta para la representación de la crisis epistemológica que detona la colonización y para el colapso de las nociones forjadas en lo unitario, sobre todo con respecto al tema de la identidad. Del mismo modo, en la elipse, tanto la experiencia del exilio como la estética neobarroca, encuentran un soporte figurativo de representación. Señala González Echeverría: "El arte del barroco es el arte de lo indirecto, de la voluta antes que la línea recta, de lo oblicuo o sesgado antes que lo frontal (...) El neobarroco será el arte de las estrategias (...) es el arte de la lejanía conquistada por medio de las figuras, que rechaza las engañosas seducciones de la identidad" (Plumas 1592).

El neobarroco de Sarduy opera dentro de un terreno en el cual todos los recursos y elementos constituyentes aparecen y se inscriben en una lógica de la resistencia: el término acuñado por el cubano en su ensayo Barroco y Neobarroco (1972) "Barroco de la Revolución” (1404), para referirse a su propia poética neobarroca y que también hace alusión al contexto político cubano de la época, tiene que ver con la idea de revolución como causa y efecto, como motivo y repercusión de la identidad latinoamericana, de la identidad cubana y de su propia identidad individual constituida en la experiencia del exilio.

\section{LA ELIPSE SARDUYANA}

El trabajo sobre la novelística de Sarduy en el cual se basa este artículo, como se mencionó, tenía como objeto proporcionar ciertas estructuras subyacentes y entradas de lectura transversales, para lo cual las siete obras fueron sometidas a un mismo mapa analítico constituido por tres categorías 
principales: el contexto de producción de la obra, la estructura narrativa y el tratamiento de ciertas nociones como teatralidad, tatuaje y deseo y, por último, la dimensión paródica del relato. Luego de observar las siete obras bajo los mismos criterios, fue posible reconocer ciertos aspectos que dotan la novelística de Sarduy de una continuidad particular.

La permanencia de ciertos escenarios, situaciones y personajes entre muchos otros aspectos da cuenta de la consciencia del autor sobre los bordes de su propio cuerpo escritural, puesto que logra franquearlos continuamente. La libertad y movilidad intra e intertextual de los personajes permite visualizar la novelística total como una gran filigrana o tejido textual, como una sola macronovela que se articula en torno a la pregunta por la cubanidad y que deviene gran relato identitario neobarroco de base múltiple. Al igual que la estructura del rizoma propuesta por Deleuze y Guattari (1980), desprovista de formas centralizadas o monolíticas de comprensión, la novelística sarduyana se configura de entramados significantes que describen la cubanidad y al mismo autor como una gran "síntesis metafórica" (Sarduy, Severo 1802), cuya configuración se vincula de manera directa al proceso de integración que exige la atomización subjetiva de la experiencia del exilio.

Casi la totalidad de las novelas de Sarduy describen una estructura narrativa circular de salida y regreso del héroe al mismo punto de inicio, a excepción de Gestos, donde la mulata protagonista permanece deambulando en el centro de la Isla sin traspasar ningún borde. La voluta, como una ola eyectada pero que pronto se vuelve sobre sí misma, se instala como estructura base de las novelas sarduyanas, donde los protagonistas realizan un viaje de autorreconocimiento, en el cual se produce una mutación de conciencia que se manifiesta tanto en el cuerpo del personaje como en su entorno. Con esto se relaciona la afirmación de Julia A. Kushigian: "Sarduy también introduce el proceso de hacerse y autocultivarse en sus obras. Esto se asocia con la autorrealización que busca definirse en el subgénero literario del Bildungsroman" (1607). La experiencia de transformación, de la "alteración", que significa cada novela tanto para el personaje como para el autor, se manifiesta en un desplazamiento $\mathrm{y}$ transformación del punto de origen desde el cual se inicia el relato/viaje, correspondiente siempre al espacio de la casona-burdel-albergue-templo. Y no solo el punto de origen, sino todo el camino de regreso recorrido por el protagonista, aun cuando éste coincida en la narración con el de salida, aparece también alterado, y es lo que hemos identificado como "La vuelta por otro camino" (Anabalón 107), motivo que se menciona repetidas veces en la novelística de Sarduy y, de manera particular, en la novela de 1990, 
Cocuyo. Como consecuencia de aquel desplazamiento del punto de origen, el trayecto del protagonista sarduyano que se suponía circular, deviene elíptico, puesto que como móvil, su detención correspondiente al punto de partida se ve obstruida por lo que es eyectado a una nueva voluta, a un nuevo relato. La novelística de Sarduy, entonces, puede ser descrita como una gran espiral narrativa neobarroca cuyo relato corresponde a un proceso de construcción identitario cubano que toma lugar en el exilio.

\section{PALABRAS AL CIERRE}

Artistas e intelectuales, quienes siempre conforman una parte importante dentro de la masa exiliada, puesto que el exilio corresponde a un método de higienización ideológica, al verse en la necesidad de generar un nuevo escenario propulsor para sus discursos y creaciones, encuentran en la subversión su terreno de acción y en la transgresión la canalización de su iniciativa de resistencia y permanente situación de inestabilidad. Así como la figura de la elipse alberga la transgresión contra toda una era de pensamiento basado en la esfera, el intelectual exiliado adopta la resistencia y la alteración como principio discursivo y forma de vida. "El exilio no es nunca un estado satisfecho, plácido o seguro del ser (...) es la vida sacada de su orden habitual. Es nómada, descentrada, contrapuntística; pero en cuanto uno se acostumbra a ella su fuerza desestabilizadora emerge de nuevo" (Said, Reflexiones 195). Las descripciones de Sarduy en torno a la elipse/is, acerca de la perturbación substancial y perpetua que significa la duplicación del centro, recuerdan las palabras de Said y abre la posibilidad de pensar un soporte figurativo para la experiencia del exilio. Conforme a la dinámica del neobarroco, la obra sarduyana, al igual que la cubanidad, que la identidad latinoamericana y que el sujeto exiliado, corresponde a un género de naturaleza intermedia, oscilante entre la literatura y aquello que Hegel reconoció como la muerte del arte, la estética: "barroca es la etapa final de todo arte, cuanto éste exhibe y dilapida sus medios" (Cit. en Villalobos 1); barroca es la autorreflexividad misma, el pensamiento crítico, la crisis moderna de la subjetividad; barroco es cuando el arte toma las riendas de sus recursos y se vuelve sobre sí mismo, como único referente. Y más allá del barroco, el neobarroco corresponde a la reformulación de la reformulación, y su referente ya no al objeto en crisis sino que a la crisis misma. La gran novela elíptica narra el aislamiento, la periferia, la multiplicidad, la oscilación y la naturaleza esencialmente revolucionaria 
de un escritor-pintor latinoamericano, cubano, camagüeyano, homosexual, exiliado y neobarroco, quien se mira a sí mismo en su propio proceso de autociframiento, de autosignificación.

\section{BIBLIOGRAFÍA}

Anabalón, Javiera. "Islas Severas. La categoría del exilio como aproximación a la estética neobarroca de Severo Sarduy". Tesis para grado de Magíster. Universidad de Chile, 2012. http://www.tesis.uchile.cl

Foucault, Michel. Las palabras y las cosas. Una arqueología de las ciencias humanas. Trad. Elsa Cecilia Frost. Buenos Aires: Siglo XXI Editores, 1968.

González Echeverría, Roberto. "Memoria de apariencias y ensayo de Cobra". En: Sarduy, Severo. Obra Completa. Tomo II. Coords. G. Guerrero y F. Wahl. Madrid: ALLCA XX/ FCE, 1999. 1750-1762.

"Plumas sí: De donde son los cantantes y Cuba". En Sarduy, Severo. Obra Completa. Tomo II. Coords. G. Guerrero y F. Wahl. Madrid: ALLCA XX/ FCE, 1999. 1582-1603.

Guerrero, Gustavo. "Severo Sarduy”. Letras Libres N²4. Diciembre 2011- Septiembre 2003. http://www.letraslibres.com/revista/entrevista/severo-sarduy

Kolakowski, Leszek. "Elogio del Exilio”. Vuelta Sudamericana. I.1 (1986): 50-52.

Kushigian, Julia. "Severo Sarduy, Orientalista Posmodernista en camino hacia la autorrealización". Une ménagerie a trois: Cobra, Colibrí y Cocuyo. 1999. En Sarduy, Severo. Obra Completa. Tomo II. Coords. G. Guerrero y F. Wahl. Madrid: ALLCA XX/ FCE, 1999. 1605-1618

Larraín, Jorge. ¿América Latina moderna? Globalización e identidad. Santiago: LOM, 2005.

Mosquera, Gerardo. "El nuevo arte cubano". Arte y Política. Eds. P. Oyarzún, N. Richard y C. Zaldivar. Santiago: Universidad ARCIS, 2005

Ortiz, Fernando. Contrapunteo cubano del tabaco y el azúcar.1940. Caracas: Ayacuyo, 1987. El engaño de las razas. La Habana: Páginas, 1946.

Rojas, Sergio. Escritura Neobarroca. Santiago: Palinodia, 2010

Rodríguez Rivera, Guillermo. Por el camino del mar. Los cubanos. La Habana Vieja: Boloña, 2005.

Said, Edward W. Reflexiones sobre el exilio. Ensayos literarios y culturales. 2001. Barcelona: Debate, 2005.

Representaciones del intelectual. Barcelona: Debate, 2007

Sarduy, Severo. "El barroco y el neobarroco". 1972. Obras Completas. Tomo II. Coords. G. Guerrero y F. Wahl. Madrid: ALLCA XX/ FCE, 1999. 1385-1403

“Barroco". 1974. Obras Completas. Tomo II. Coords. G. Guerrero y F. Wahl. Madrid: ALLCA XX/ FCE, 1999. 1197-1264

"Entrevista". A Fondo. Por Joaquín Soler Cerrano. España: Radiotelevisión Española TVE, 1976. <https://www.youtube.com/watch?v=hc8ieKHsc6Y 
“La Simulación”. 1982. Obras Completas. Tomo II. Coords. G. Guerrero y F. Wahl. Madrid: ALLCA XX/ FCE, 1999.

“Nueva Inestabilidad”. 1987. Obras Completas. Tomo II. Coords. G. Guerrero y F. Wahl. Madrid: ALLCA XX/ FCE, 1999. 1347-1384.

“Severo Sarduy". Entr. Emir Rodríguez Monegal. Obra Completa. Tomo II. Coords. G. Guerrero y F. Wahl. Madrid: ALLCA XX/ FCE, 1999. 1795-1811.

Villalobos, Sergio. Barroco y soberanía: el problema de la escatología politica. California: Berkeley. Viernes 18 de octubre, 2013. https:/www.academia.edu/4842455/Barroco_y_ soberan $\% \mathrm{C} 3 \% \mathrm{Ada}$ 